\title{
Cardiovascular guidelines: separate career may help attenuate controversy
}

\author{
Katherine Esposito ${ }^{1 *}$, Antonio Ceriello ${ }^{2,3}$, Stefano Genovese ${ }^{4}$ and Dario Giugliano ${ }^{5}$
}

\begin{abstract}
The release of recent guidelines for high cholesterol, hypertension and diabetes in the U.S. has been accompanied by great noise and concerns, both in the academic circuits and the lay press. For persons aged 40 to 75 years, with LDL cholesterol levels between $70-189 \mathrm{mg} / \mathrm{dL}$ and $7.5 \%$ or higher estimated 10-year risk, the peril of a global "statinization" has been advocated, predicting a 70\% increase of statin use in this otherwise healthy people. A minority of the Eight Joint National Committee panel disagreed with the recommendation to increase the target systolic blood pressure from 140 to $150 \mathrm{mmHg}$ in persons aged 60 years or older without diabetes mellitus or chronic kidney disease. The 2013-American Association of Clinical Endocrinologists algorithm and consensus statement on diabetes has been criticized with particular concerns about transparency, conflicts of interest, group composition, and the abundant use of personal judgment and experience instead of rigorous methodology. Separate careers for experts who collect evidence from persons who write the actual guidelines seems a good opportunity in order to attenuate the noise associated with release of new guidelines, especially those that counter prior practice.
\end{abstract}

\section{Introduction}

"Patients and the public benefit when physicians and researchers collaborate with pharmaceutical, medical device, and biotechnology companies to develop products that benefit individual and public health. At the same time, concerns are growing that wide-ranging financial ties to industry may unduly influence professional judgments involving the primary interests and goals of medicine. Such conflicts of interest threaten the integrity of scientific investigations, the objectivity of professional education, the quality of patient care, and the public's trust in medicine" [1].

On 13 November 2013, from the columns of the New York Times (http://www.nytimes.com/2013/11/14/opinion/dont-give-more-patients-statins.html?_r=0), Abramson and Redberg exhorted healthy Americans to focus on the real factors that undeniably reduce the risk of heart disease (healthy diets, exercise, avoiding smoking) and not on statin prevention, as suggested by the new cholesterol guidelines from the American College of Cardiology (ACC) and the American Heart Association (AHA) [2]. The new, longawaited and much anticipated, hypertension guidelines

\footnotetext{
* Correspondence: katherine.esposito@unina2.it

${ }^{1}$ Department of Clinical and Experimental Medicine, Second University of Naples, Naples, Italy

Full list of author information is available at the end of the article
}

from the Eighth Joint National Committee (JNC8) [3] are even criticized by members of the very panel that developed them [4]. The validity of the 2013-American Association of Clinical Endocrinologists (AACE) algorithm and consensus statement on diabetes [5] has fiercely been questioned [6]. Are all these concerns intellectually and scientifically justified, or are they related to the evidence that guidelines per se generate controversy, given the complexity of the task and the limitations of available evidence?

\section{The ACC/AHA cholesterol guidelines}

The ACC/AHA guidelines on the treatment of blood cholesterol [2] recommends moderate- to high-intensity statin therapy for primary prevention for the following groups (class I recommendations): (1) persons with lowdensity lipoprotein (LDL) cholesterol levels of $190 \mathrm{mg} / \mathrm{dL}$ or higher; (2) persons aged 40 to 75 years with type 1 or 2 diabetes; or (3) persons aged 40 to 75 years with LDL cholesterol levels between 70 and $189 \mathrm{mg} / \mathrm{dL}$ and $7.5 \%$ or higher estimated 10-year risk of atherosclerotic cardiovascular disease. The peril of a global "statinization" of the planet for this grey zone of cardiovascular risk has been put forward [7], predicting an increase of healthy people for whom statins are recommended by nearly 70 percent (about 920 million people around the world would be 
classified in this risk categories), and a cumulative global sales of statins approaching $\$ 1$ trillion by 2020 . Critics also point out that 8 of the 15 panelists of the new cholesterol guidelines had industry ties [8].

\section{THE JNC8 hypertension guidelines}

Only about half of patients with hypertension in the United States actually have an systolic blood pressure (SBP) of $140 \mathrm{~mm} \mathrm{Hg}$ or less [9]. The Joint National Committee (JNC7) Guidelines [10], released more than a decade ago, concluded that all adult patients with hypertension (regardless of their age) should have their $\mathrm{BP}$ reduced to a SBP of lower than $140 \mathrm{~mm} \mathrm{Hg}$, with even tighter control in patients with diabetes or renal disease (SBP $<130 \mathrm{mmHg}$ ). In contrast, the current recommendation [3] raises target SBP goals to $150 \mathrm{~mm} \mathrm{Hg}$ or lower in those aged 60 years or older, while eliminating the tighter control recommendations in patients with diabetes and renal disease. A minority of the panel disagreed with the recommendation to increase the target SBP from 140 to $150 \mathrm{mmHg}$ in persons aged 60 years or older without diabetes mellitus or chronic kidney disease [4]. Intuitively, an estimated 13 million U.S. hypertensive treated people aged 60 years or older [11] would reduce pill intake as the SBP goal increase from 140 to $150 \mathrm{mmHg}$. Antihypertensive medication use may be associated with injurious falls in the elderly, a $30 \%$ to $40 \%$ increased risk compared with no antihypertensive medication use [12]. Moreover, the results of the ACCORD MIND [13] show that intensive management to a target SBP of less than $120 \mathrm{~mm} \mathrm{Hg}$ and fibrate therapy in the context of LDL cholesterol level control are not effective in reducing cognitive decline in persons with poorly controlled type 2 diabetes at high risk for cardiovascular disease.

\section{The AACE diabetes guidelines}

The 2013-AACE algorithm and consensus statement on diabetes [5] has been criticized with particular concerns about transparency, conflicts of interest, group composition, and the abundant use of personal judgment and experience instead of rigorous methodology [6]. Despite all these concerns, the ultimate feeling is that the major concern relates to the financial ties. Most panel members, including the chair, of the diabetes AACE guidelines had financial conflicts of interest [6], and many of the financial associations were with companies that sell diabetes medications that figure prominently in the algorithm and consensus statement.

\section{Producing guidelines: a hard job}

Producing guidelines in the United States has become increasingly more complicated and contentious. The presence of conflicts of interest is a common source of controversy, with claims that recommendations are designed to fill the pockets of those who would profit from the interventions advocated [14]. All this leaves patients and clinicians perplexed and distrustful of guidelines, adding uncertainty to an imperfect science, as Medicine is. However, scientific U.S. guidelines deeply impact on the prescription patterns of thousands of clinicians, and on the health needs of millions of patients worldwide. All the story also demonstrates that even in topic areas (high cholesterol, hypertension, diabetes) with extensive amounts of data and published clinical trials, crucial evidence is still missing.

Approximately 2500 guidelines are operative in the U. S. (www.guideline.gov) with the aim to improve clinical guidance: about three-fifths were issued by a medical specialty society or a professional association. Even considering overlapping and homonymy, it seems reasonable to suppose that thousands of experts are involved in U.S. medical guidelines. But, who is an expert? A person who is very knowledgeable about or skilful in a particular area (Oxford Dictionaries); in the medical field, an expert is supposed to be a clinician with a solid scientific reputation and skilled experience in clinical care. Paradoxically, the scientific reputation of an expert may be based on clinical trials that are, for the most, sponsored by industry. Putting an expert among panel members for its capacity to attract media attention, should be nuanced by the high likelihood for financial conflicts of interest. In a recent cross-sectional study [15] evaluating 45 guidelines from Danish clinical specialty societies, $96 \%$ of guidelines had one or more authors with a conflict of interest (independent validation), but only $2 \%$ disclosed author conflicts of interest. Moreover, only $22 \%$ of guidelines described the methods used for guideline development and $24 \%$ graded the types of evidence.

\section{A suggested way out}

Is there a honorable way out? For clinicians, who are called to operate a personal choice, based on clinical judgment, among the many guidelines release by reputed scientific associations; for experts, whose reputation may suffer from these reflections; and for the millions of people whose care may be affected. It may be hard to imagine that professional societies and scientific organizations can renounce to industry funding, especially in times, as the present, of financial shortage. Not surprisingly, important members of these societies or organizations may be the same experts called for writing guidelines. There is agreement that "clinicians and patients are most likely to pay attention to recommendations that are formulated by independent experts without funding from industry" [16]. A multidisciplinary panel with members who have no substantial financial and intellectual conflicts of interest is essential, also for attracting the attention of clinicians and patients to any clinical guideline. However, the 
search of experts without funding from industry may be unproductive, and freedom from any conflict (not only financial) can be difficult to ascertain. The American Cancer Society methodology aligns with the Institute of Medicine principles for trustworthy clinical guideline development, particularly by separating the processes of specialty input and evidence synthesis from writing of the actual guideline [17]. Separate careers for experts who collect evidence from persons who write the actual guidelines seems a good opportunity in order to attenuate the rumors associated with release of new guidelines, especially those that counter prior practice. Inclusion of multiple stakeholders during guideline development, evidence reviews that are fully available for scrutiny before a guideline is finalized, and refraining from turning the release of new or updated guidelines into media events [14] may also help.

\section{Competing interests}

The authors take full responsibility for the content of this article. Dario Giugliano serves as guarantor. KE, AC, SG, and DG received consultancy fees, attended advisory boards or have held lectures for a number of pharmaceutical companies producing antidiabetic drugs.

\section{Authors' contributions}

KE and DG wrote the manuscript. All authors revised the article for important intellectual content. All authors read and approved the final manuscript.

\section{Author details}

'Department of Clinical and Experimental Medicine, Second University of Naples, Naples, Italy. ${ }^{2}$ Institut d'Investigations Biomèdiques August Pi i Sunyer (IDIBAPS), Barcelona, Spain. ${ }^{3}$ Centro de Investigacion Biomèdica en Red de Diabetes y Enfermedades Metabolicas Asociadas (CIBERDEM), Barcelona, Spain. ${ }^{4}$ Department of Cardiovascular and Metabolic Diseases, IRCCS Multimedica, Sesto San Giovanni, Milan, Italy. ${ }^{5}$ Department of Medical, Surgical, Neurological, Metabolic Sciences and Aging, Second University of Naples, Naples, Italy.

Received: 5 March 2014 Accepted: 15 March 2014

Published: 28 March 2014

\section{References}

1. Lo B, Field MJ: Conflict of interest in medical research, education and practice. Washington: National Academies Press (US); 2009.

2. Stone NJ, Robinson J, Lichtenstein AH, Bairey Merz CN, Lloyd-Jones DM, Blum CB, McBride P, Eckel RH, Schwartz JS, Goldberg AC, Shero ST, Gordon D, Smith SC Jr, Levy D, Watson K, Wilson PWF: ACC/AHA Guideline on the treatment of blood cholesterol to reduce atherosclerotic cardiovascular risk in adults. Circulation 2013. [published online ahead of print November 12. 2013] doi:10.1161/01.cir.0000437738.63853.7a

3. James PA, Oparil S, Carter BL, Cushman WC, Dennison-Himmelfarb C, Handler J, Lackland DT, LeFevre ML, MacKenzie TD, Ogedegbe O, Smith SC Jr, Svetkey LP, Taler SJ, Townsend RR, Wright JT Jr, Narva AS, Ortiz E: 2014 evidence-based guideline for the management of high blood pressure in adults: report from the panel members appointed to the Eighth Joint National Committee (JNC 8). JAMA 2014, 311(5):507-520.

4. Wright JT Jr, Fine L, Lackland DT, Ogedegbe G, Dennison Himmelfarb CR: Evidence supporting a systolic blood pressure goal of less than $150 \mathrm{~mm}$ $\mathrm{Hg}$ in patients aged 60 years or older: the minority view. Ann Intern Med 2014. doi:10.7326/M13-2981.

5. Garber AJ, Abrahamson MJ, Barzilay Jl, Blonde L, Bloomgarden ZT, Bush MA, Dagogo-Jack S, Davidson MB, Einhorn D, Garvey WT, Grunberger G, Handelsman Y, Hirsch IB, Jellinger PS, McGill JB, Mechanick Jl, Rosenblit PD, Umpierrez G, Davidson MH, American Association of Clinical Endocrinologists: AACE comprehensive diabetes management algorithm 2013 consensus statement: executive summary. Endocr Pract 2013, 19(2):536-557.
6. Gionfriddo MR, McCoy RG, Lipska KJ: The 2013 American Association of Clinical Endocrinologists' Diabetes Mellitus Management Recommendations. Improvements needed. JAMA Intern Med 2014, 174(2):179-180.

7. Ioannidis JPA: More than a billion people taking statins? Potential implications of the new cardiovascular guidelines. JAMA 2014, 311(5):463-464.

8. Lenzer J: Majority of panelists on controversial new cholesterol guideline have current or recent ties to drug manufacturers. BMJ 2013, 347:66989.

9. Go AS, Bauman M, King SM, Fonarow GC, Lawrence W, Williams KA, Sanchez E: An effective approach to high blood pressure control: a science advisory from the American Heart Association, the American College of Cardiology, and the Centers for Disease Control and Prevention. Hypertension. [published online November 15, 2013] doi:10.1161/HYP.0000000000000003.

10. Chobanian AV, Bakris GL, Black HR, Cushman WC, Green LA, Izzo JL Jr, Jones DW, Materson BJ, Oparil S, Wright JT Jr, Roccella EJ, National Heart, Lung, and Blood Institute Joint National Committee on Prevention, Detection, Evaluation, and Treatment of High Blood Pressure; National High Blood Pressure Education Program Coordinating Committee: The seventh report of the joint national committee on prevention, detection, evaluation, and treatment of high blood pressure: the JNC 7 report. JAMA 2003, 289(19):2560-2572.

11. Go AS, Mozaffarian D, Roger V, Benjamin EJ, Berry JD, Blaha MJ, Dai S, Ford ES, Fox CS, Franco S, Fullerton HJ, Gillespie C, Hailpern SM, Heit JA, Howard VJ, Huffman MD, Judd SE, Kissela BM, Kittner SJ, Lackland DT, Lichtman JH, Lisabeth LD, Mackey RH, Magid DJ, Marcus GM, Marelli A, Matchar DB, McGuire DK, Mohler ER III, Moy CS, et al: AHA Statistical Update. Heart Disease and Stroke Statistics-2014 Update. A Report From the American Heart Association. Circulation 2014, 129(3):e28-e292.

12. Tinetti ME, Han L, Lee DSH, McAvay, Peduzzi P, Gross CP, Zhou B, Haiqun Lin $\mathrm{H}$ : Antihypertensive medications and serious fall injuries in a nationally representative sample of older adults. JAMA Intern Med. [published online February 24, 2014] doi:10.1001/jamainternmed.2013.14764.

13. Williamson JD, Launer LJ, Bryan RN, Coker LH, Lazar RM, Gerstein HC, Murray AM, Sullivan MD, Horowitz KR, Ding J, Marcovina S, Lovato L, Lovato J, Margolis KL, Davatzikos C, Barzilay J, Ginsberg HN, Linz PE, Miller ME, Action to Control Cardiovascular Risk in Diabetes (ACCORD) Memory in Diabetes (MIND) Investigators: Cognitive function and brain structure in persons with type 2 diabetes mellitus after intensive lowering of blood pressure and lipid levels: a randomized clinical trial. JAMA Intern Med. [published online February 3, 2014] doi:10.1001/jamainternmed.2013.13656.

14. Guallar E, Laine C: Controversy over clinical guidelines: Listen to the evidence, not the noise. Annals Intern Med. published online first at www.annals.org on 28 January 2014.

15. Bindslev JB, Schroll J, Gotzsche PC, Lundh A: Underreporting of conflicts of interest in clinical practice guidelines: cross sectional study. BMC Med Ethics 2013, 14:19.

16. Steinbrook R: Guidance for guidelines. N Engl J Med 2007, 356(4):331-333.

17. Brawley O, Byers T, Chen A, Pignone M, Ransohoff D, Schenk M, Smith R, Sox H, Thorson AG, Wender R: New American Cancer Society process for creating trustworthy cancer screening guidelines. JAMA 2011, 306(22):2495-2499

\section{doi:10.1186/1475-2840-13-66}

Cite this article as: Esposito et al.: Cardiovascular guidelines: separate career may help attenuate controversy. Cardiovascular Diabetology 2014 13:66. 